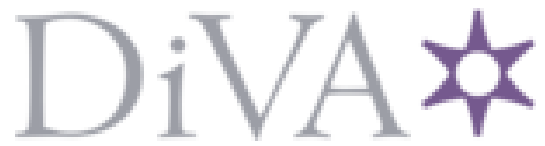

http://www.diva-portal.org

Postprint

This is the accepted version of a paper presented at 2019 22nd International Conference on Electrical Machines and Systems (ICEMS).

Citation for the original published paper:

Bitsi, K., Wallmark, O., Bosga, S. (2019)

An Induction Machine with Wound Independently-Controlled Stator Coils

In: Harbin, China

https://doi.org/10.1109/ICEMS.2019.8921779

N.B. When citing this work, cite the original published paper.

Permanent link to this version:

http://urn.kb.se/resolve?urn=urn:nbn:se:kth:diva-266350 


\section{An Induction Machine with Wound Independently-Controlled Stator Coils}

\author{
Konstantina Bitsi \\ Division of Electric Power \\ and Energy Systems \\ KTH Royal Institute of Technology \\ Stockholm, Sweden \\ bitsi@kth.se
}

\author{
Oskar Wallmark \\ Division of Electric Power \\ and Energy Systems \\ KTH Royal Institute of Technology \\ Stockholm, Sweden \\ owa@kth.se
}

\author{
Sjoerd Bosga \\ $A B B$ Corporate Research \\ Västerås, Sweden \\ sjoerd.bosga@se.abb.com
}

\begin{abstract}
In this paper, a novel induction machine topology with wound, independently-controlled stator coils is presented. The introduced configuration of the stator-winding enables the individual energization and control of the coils in each stator slot. Therefore, the possibility of changing the number of poles and active phases in the stator winding during operation is explored in this study.
\end{abstract}

Keywords- Asynchronous rotor, independently-controlled stator coils, phase-changing capability, pole-changing capability

\section{INTRODUCTION}

The deployment of electric vehicles in the transportation sector is considered a viable solution towards reducing the global greenhouse-gas emissions and fossil-fuel consumption [1]. In order to produce highly efficient and economically feasible electrical drive systems, the selection of appropriate electrical-traction motor designs is a key step. Taking into account the disadvantages of the use of permanent magnets in synchronous motors (including high costs, dependence on rare-earth materials and problems with demagnetization), induction motors should always be considered as a reliable and cost-effective alternative.

An innovative induction machine topology is introduced in [2], where an asynchronous rotor is combined with a multiphase stator cage winding. This winding is composed of solid aluminum bars in every stator slot, which are short-circuited at one axial end of the machine using an end-ring. Thus, each stator slot corresponds to a potentially separate phase winding and can be individually supplied. Consequently, the structure of the stator winding in this machine design facilitates the possibility of changing the number of pole-pairs as well as the number of active phases during operation [2]. However, although the usage of solid conductors in the stator cage offers the benefits of higher fill factor and potentially higher efficiency and better thermal behavior, this configuration results in very high current levels in the DC supply [3]. Therefore, the design of the converter and the battery configuration needs to be reconsidered, as such high current levels (in the order of $15 \mathrm{kA}$ peak current [3]) are not compatible with the high-voltage battery systems that are currently available in the electric-vehicle market [4].

In order to decrease the high current levels rising in the aforementioned topology, the solid bars in each stator slot can be replaced with multi-turn coils that are wound axially along the stator core (Gramme-type winding [5]) and are shortcircuited at one axial end. In this way, a machine design that is compatible with the present-day high-voltage battery system can be produced, while the useful capabilities of polechanging and phase-changing of the topology of [2] can still be harnessed. Therefore, in this paper, this induction machine

This research project is supported in part by the Swedish Energy Agency. with wound independently-controlled stator coils (WICSC) is investigated. The developed finite-element (FE) model is shown in Fig. 1a for the WICSC geometry of 36 stator slots (i.e. coils) and 26 rotor bars. The connection between the multi-turn stator coils $\left(\mathrm{C}_{\mathrm{S}, 1}-\mathrm{C}_{\mathrm{S}, 36}\right)$ that are wound axially around the stator core is visualized in a simplified schematic in Fig. $1 b$.

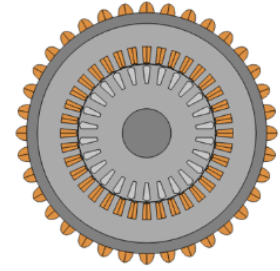

(a)

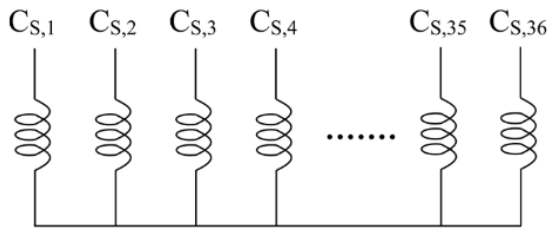

(b)
Fig. 1. (a) 2-D FE model of the WICSC machine and (b) simplified schematic showing the connection between the stator coils.

This paper is organized as follows: in Section II, the steadystate equivalent circuit of the topology is derived and analytical estimations of the current scaling are provided for implementing pole-changing and phase-changing during operation. Section III focuses on the development of the FE model of the WICSC machine and demonstrates its numerically estimated electromagnetic behavior in polechanging and phase-changing states.

\section{ANALYTICAL APPROACH}

\section{A. MMF from a Balanced m-Phase Stator Winding}

In order to generalize the machine model regardless of the number of phases (odd or even), the stator current excitation is expressed based on a methodology that utilizes pole symmetry instead of stator-periphery symmetry (i.e. symmetric with respect to $\pi$ instead of $2 \pi$ ). This concept is introduced as pole-symmetric fundamental winding configuration in [6], while it is also mentioned in [7] as conventional winding arrangement. For this study, the terminology used in [6] will be employed. Examples of converting the 3-phase and the asymmetrical 6-phase stator currents from the practical (customary) winding configuration to the fundamental winding configuration are shown in Fig. 2.

Based on the above assumptions, if a balanced, sinusoidal $\mathrm{m}$-phase current excitation is considered in the stator winding, the current in phase $\mathrm{n}$ can be expressed as:

$$
i_{s, n}=\hat{i}_{s} \cos \left(\omega_{s} t-(n-1) \frac{\pi}{m}\right)
$$

where $\hat{1}_{\mathrm{s}}$ is the stator current amplitude and $\omega_{\mathrm{s}}$ the angular electrical frequency. 

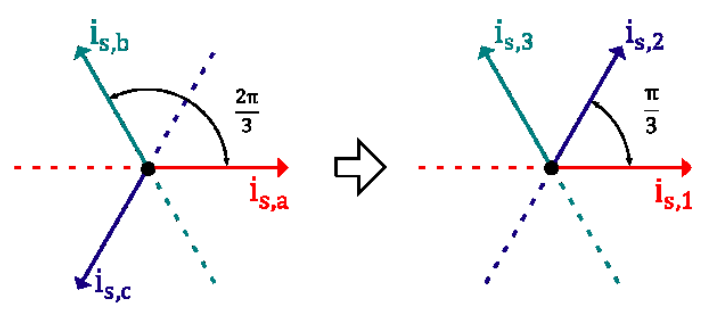

(a)
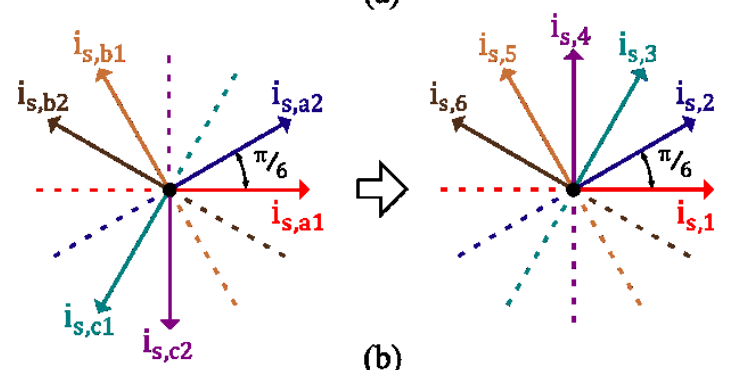

(b)

Fig. 2. Transformation from the practical winding configuration to the fundamental winding configuration for (a) a 3-phase current excitation and (b) an asymmetrical 6-phase current excitation.

Supposing that the coils of each phase are series connected, the resulting magnetomotive force (MMF) in the air-gap due to the stator current in phase $\mathrm{n}$ is found as:

$$
F_{w, n}=\frac{n_{s} i_{s, n} Q_{s}}{\pi m} \sum_{h} \frac{k_{h}}{h} \sin \left(h\left(\theta-(n-1) \frac{2 \pi}{m p}\right)\right)
$$

where $Q_{s}$ is the number of stator slots, $n_{s}$ the number of winding conductors per stator slot, $\mathrm{k}_{\mathrm{h}}$ the winding factor for harmonic $h$, and $\theta$ a mechanical angle spanning along the airgap. Thus, the total MMF waveform in the air-gap due to the $\mathrm{m}$-phase current excitation in the stator can be obtained as follows:

$\mathrm{F}_{\mathrm{s}}=\sum_{\mathrm{n}=1}^{\mathrm{m}} \mathrm{F}_{\mathrm{w}, \mathrm{n}}=$

$\frac{\mathrm{n}_{\mathrm{s}} \hat{\mathrm{s}}_{\mathrm{s}} \mathrm{Q}_{\mathrm{s}}}{2 \pi \mathrm{m}} \sum_{\mathrm{n}=1}^{\mathrm{m}} \sum_{\mathrm{h}} \frac{\mathrm{k}_{\mathrm{h}}}{\mathrm{h}} \sin \left(\mathrm{h} \theta+\omega_{\mathrm{s}} \mathrm{t}-(\mathrm{n}-1) \frac{\pi}{\mathrm{m}}\left(\frac{\mathrm{h}}{\mathrm{p} / 2}+1\right)\right)+$

$\frac{\mathrm{n}_{\mathrm{s}} \hat{\mathrm{i}}_{\mathrm{s}} \mathrm{Q}_{\mathrm{s}}}{2 \pi \mathrm{m}} \sum_{\mathrm{n}=1}^{\mathrm{m}} \sum_{\mathrm{h}} \frac{\mathrm{k}_{\mathrm{h}}}{\mathrm{h}} \sin \left(\mathrm{h} \theta-\omega_{\mathrm{s}} \mathrm{t}-(\mathrm{n}-1) \frac{\pi}{\mathrm{m}}\left(\frac{\mathrm{h}}{\mathrm{p} / 2}-1\right)\right)$

\section{B. MMF from the Induced Rotor-Bar Currents}

The flux-density distribution in the air-gap caused by the stator excitation is assumed to induce sinusoidal currents in the rotor bars with the angular electrical frequency $\omega_{\text {slip }}$. This frequency is linked with the electrical frequency $\omega_{\mathrm{s}}$ through the slip, $s$ of the machine: $\omega_{\text {slip }}=s \omega_{\mathrm{s}}$. The rotor bar current in bar $v$ can, hence, be expressed as:

$$
\mathrm{i}_{\mathrm{r}, v}=\hat{\mathrm{i}}_{\mathrm{r}} \sin \left(\omega_{\text {slip }} \mathrm{t}-(v-1) \frac{\pi \mathrm{p}}{\mathrm{Q}_{\mathrm{r}}}\right)
$$

where $\hat{\imath}_{r}$ is the rotor-bar current amplitude and $Q_{r}$ the number of rotor bars.

It is evident from (4) that the rotor can be practically considered as a poly-phase winding that is composed of $Q_{r} / p$ phases. Assuming an angle spanning along the air-gap fixed to the rotor, $\theta_{\mathrm{m}}$, the resulting air-gap MMF distribution due to the rotor-bar current $i_{r, v}$ can be found as:

$$
\mathrm{F}_{\mathrm{b}, v}=\frac{\mathrm{pi} \mathrm{r}_{\mathrm{r}, v}}{\pi} \sum_{\mathrm{h}} \frac{1}{\mathrm{~h}} \sin \left(\mathrm{h}\left(\theta_{\mathrm{m}}-(v-1) \frac{2 \pi}{\mathrm{Q}_{\mathrm{r}}}\right)\right)
$$

Consequently, the total MMF waveform in the air-gap due to the $Q_{r} / p$-phase rotor-bar excitation can be obtained as follows:

$$
\begin{aligned}
& \mathrm{F}_{\mathrm{r}}=\sum_{v=1}^{\mathrm{Q}_{\mathrm{r}} / \mathrm{p}} \mathrm{F}_{\mathrm{b}, v}= \\
& \frac{\mathrm{pi}_{\mathrm{r}, v}}{2 \pi} \sum_{v=1}^{\frac{\mathrm{Qr}}{p}} \sum_{\mathrm{h}} \frac{1}{\mathrm{~h}} \cos \left(\mathrm{h} \theta_{\mathrm{m}}-\omega_{\text {slip }} \mathrm{t}-(v-1) \frac{\pi}{\mathrm{m}}\left(\frac{\mathrm{h}}{\mathrm{p} / 2}-1\right)\right)- \\
& \frac{\mathrm{pi}_{\mathrm{r}, v}}{2 \pi} \sum_{v=1}^{\frac{\mathrm{Qr}}{p}} \sum_{\mathrm{h}} \frac{1}{\mathrm{~h}} \cos \left(\mathrm{h} \theta_{\mathrm{m}}+\omega_{\text {slip }} \mathrm{t}-(v-1) \frac{\pi}{\mathrm{m}}\left(\frac{\mathrm{h}}{\mathrm{p} / 2}+1\right)\right)(6)
\end{aligned}
$$

\section{Stator and Rotor Inductances}

In order to derive the equivalent-circuit WICSC machine model, the coupling between a single stator phase to a single rotor bar is considered. The flux linkage per stator phase, $\psi_{\mathrm{s}}$, can be defined as:

$$
\psi_{\mathrm{s}}=\mathrm{L}_{\mathrm{self}, \mathrm{s}} \mathrm{i}_{\mathrm{s}, 1}+\mathrm{L}_{\lambda, \mathrm{s}} \mathrm{i}_{\mathrm{s}, 1}+\mathrm{L}_{\mathrm{mut}, \mathrm{s}-\mathrm{r}} \mathrm{i}_{\mathrm{r}, 1}
$$

where $L_{\text {self,s }}$ is the per stator-phase self inductance, $L_{\lambda, s}$ the per stator-phase leakage inductance and $L_{m u t, s, 1-r, 1}$ the per stator-phase mutual inductance resulting in stator flux due to the rotor bar current.

In a similar way, the flux linkage per rotor bar, $\psi_{\mathrm{r}}$, can be expressed as:

$$
\psi_{\mathrm{r}}=\mathrm{L}_{\text {self,r }} \mathrm{i}_{\mathrm{r}, 1}+\mathrm{L}_{\lambda, \mathrm{r}} \mathrm{i}_{\mathrm{r}, 1}+\mathrm{L}_{\text {mut,r-s }} \mathrm{i}_{\mathrm{s}, 1}
$$

where $L_{\text {self,r }}$ is the per rotor-bar self inductance, $L_{\lambda, r}$ the per rotor-bar leakage inductance and $\mathrm{L}_{\text {mut,r-s }}$ the per rotor-bar mutual inductance resulting in rotor flux due to the stator current.

The air-gap flux density of the main harmonic $(h=p / 2)$ due to the stator currents, $B_{s, p / 2}$ can be expressed as:

$$
\mathrm{B}_{\mathrm{s}, \mathrm{p} / 2}=\frac{\mu_{0} \mathrm{~F}_{\mathrm{s}, \mathrm{p} / 2}}{\delta}=\frac{\mu_{0} \mathrm{n}_{\mathrm{s}} \hat{\mathrm{i}}_{\mathrm{s}} \mathrm{Q}_{\mathrm{s}} \mathrm{k}_{\mathrm{p} / 2}}{\mathrm{p} \pi \delta} \sin \left(\frac{\mathrm{p}}{2} \theta-\omega_{\mathrm{s}} \mathrm{t}\right)
$$

where $\delta$ is the air-gap length of the WICSC machine.

In order to express the air-gap flux density of the main harmonic due to the rotor-bar excitation, $\mathrm{B}_{\mathrm{r}, \mathrm{p} / 2}$, an angle fixed to the stator should be used. This can be achieved by replacing in our analysis $\theta_{m}$ with $\theta-\omega_{\text {mech }} t$, where $\omega_{\text {mech }}$ is the angular mechanical frequency of the rotor:

$$
\omega_{\text {mech }}=\frac{\omega_{\mathrm{s}}-\omega_{\text {slip }}}{p / 2}
$$

Following the concept that was explained above, $\mathrm{B}_{\mathrm{r}, \mathrm{p} / 2}$ can now be expressed as:

$$
\mathrm{B}_{\mathrm{r}, \mathrm{p} / 2}=\frac{\mu_{0} \mathrm{~F}_{\mathrm{r}, \mathrm{p} / 2}}{\delta}=\frac{\mu_{0} \hat{\mathrm{i}}_{\mathrm{r}} \mathrm{Q}_{\mathrm{r}}}{\pi \mathrm{p} \delta} \cos \left(\frac{\mathrm{p}}{2} \theta-\omega_{\mathrm{s}} \mathrm{t}\right)
$$


The stator and rotor inductances can be found based on the following equations [8]:

$$
\begin{aligned}
\mathrm{L}_{\text {self }, \mathrm{s}}= & \frac{\mathrm{L}_{\mathrm{a}} \mathrm{r}_{\mathrm{r}}}{\mathrm{i}_{\mathrm{s}, 1}{ }^{2}} \int_{0}^{2 \pi} \mathrm{B}_{\mathrm{s}, \mathrm{p} / 2} \mathrm{~F}_{\mathrm{w}, 1, \mathrm{p} / 2} \mathrm{~d} \theta=\frac{2 \mu_{0} \mathrm{n}_{\mathrm{s}}{ }^{2} \mathrm{Q}_{\mathrm{s}}{ }^{2} \mathrm{~L}_{\mathrm{a}} \mathrm{r}_{\mathrm{r}} \mathrm{k}_{\mathrm{p} / 2}{ }^{2}}{\pi \delta \mathrm{p}^{2} \mathrm{~m}} \\
\mathrm{~L}_{\mathrm{self}, \mathrm{r}} & =\frac{\mathrm{L}_{\mathrm{a}} \mathrm{r}_{\mathrm{r}}}{\mathrm{i}_{\mathrm{s}, 1}{ }^{2}} \int_{0}^{2 \pi / p} \mathrm{~B}_{\mathrm{r}, \mathrm{p} / 2} \mathrm{~F}_{\mathrm{b}, 1, \mathrm{p} / 2} \mathrm{~d} \theta=\frac{2 \mu_{0} \mathrm{Q}_{\mathrm{r}} \mathrm{L}_{\mathrm{a}} \mathrm{r}_{\mathrm{r}}}{\pi \delta \mathrm{p}^{2}} \\
\mathrm{~L}_{\mathrm{mut}, \mathrm{s}-\mathrm{r}} & =\frac{\mathrm{L}_{\mathrm{a}} \mathrm{r}_{\mathrm{r}}}{\mathrm{i}_{\mathrm{s}, 1} \hat{1}_{\mathrm{r}} \sin \left(\omega_{\mathrm{s}} \mathrm{t}\right)} \int_{0}^{2 \pi} \mathrm{B}_{\mathrm{r}, \mathrm{p} / 2} \mathrm{~F}_{\mathrm{w}, 1, \mathrm{p} / 2} \mathrm{~d} \theta \\
& =\frac{2 \mu_{0} \mathrm{n}_{\mathrm{s}} \mathrm{Q}_{\mathrm{s}} \mathrm{Q}_{\mathrm{r}} \mathrm{L}_{\mathrm{a}} \mathrm{r}_{\mathrm{r}} \mathrm{k}_{\mathrm{p} / 2}}{\pi \delta \mathrm{p}^{2} \mathrm{~m}} \\
\mathrm{~L}_{\text {mut }, \mathrm{r}-\mathrm{s}} & =\frac{\mathrm{L}_{\mathrm{a}} \mathrm{r}_{\mathrm{r}}}{\mathrm{i}_{\mathrm{s}, 1} \hat{1}_{\mathrm{r}} \sin \left(\omega_{\mathrm{s}} \mathrm{t}\right)} \int_{0}^{2 \pi / p} \mathrm{~B}_{\mathrm{s}, \mathrm{p} / 2} \mathrm{~F}_{\mathrm{b}, 1, \mathrm{p} / 2} \mathrm{~d} \theta \\
& =\frac{2 \mu_{0} \mathrm{n}_{\mathrm{s}} \mathrm{Q}_{\mathrm{s}} \mathrm{L}_{\mathrm{a}} \mathrm{r}_{\mathrm{r}} \mathrm{k}_{\mathrm{p} / 2}}{\pi \delta \mathrm{p}}
\end{aligned}
$$

where $L_{a}$ is the active axial length and $r_{r}$ the rotor radius.

By utilizing the above stator and rotor inductances' equations, (7) and (8) can be finally re-expressed as:

$$
\begin{gathered}
\psi_{\mathrm{s}}=\mathrm{L}_{\lambda, \mathrm{s}} \mathrm{i}_{\mathrm{s}, 1}+\mathrm{L}_{\mathrm{m}}\left(\mathrm{i}_{\mathrm{s}, 1}+\mathrm{i}_{\mathrm{r}, 1}^{\prime}\right) \\
\psi_{\mathrm{r}}^{\prime}=\mathrm{L}_{\lambda, \mathrm{r}^{\prime}{ }_{\mathrm{r}, 1}}^{\prime}+\mathrm{L}_{\mathrm{m}}\left(\mathrm{i}_{\mathrm{s}, 1}+\mathrm{i}_{\mathrm{r}, 1}^{\prime}\right)
\end{gathered}
$$

where $\mathrm{L}_{\mathrm{m}}$ is the magnetizing inductance and together with $\mathrm{i}_{\mathrm{r}, 1}^{\prime}, \psi_{\mathrm{r}}^{\prime}$ and $\mathrm{L}_{\lambda, \mathrm{r}}^{\prime}$ are defined as follows:

$$
\begin{gathered}
\mathrm{L}_{\mathrm{m}}=\frac{2 \mu_{0} \mathrm{n}_{\mathrm{s}}{ }^{2} \mathrm{Q}_{\mathrm{s}}{ }^{2} \mathrm{~L}_{\mathrm{a}} \mathrm{r}_{\mathrm{r}} \mathrm{k}_{\mathrm{p} / 2}{ }^{2}}{\pi \delta \mathrm{p}^{2} \mathrm{~m}} \\
\mathrm{i}_{\mathrm{r}}^{\prime}=\frac{\mathrm{Q}_{\mathrm{r}}}{\mathrm{n}_{\mathrm{s}} \mathrm{Q}_{\mathrm{s}} \mathrm{k}_{\mathrm{p} / 2}} \mathrm{i}_{\mathrm{r}} \\
\Psi_{\mathrm{r}}^{\prime}=\frac{\mathrm{n}_{\mathrm{s}} \mathrm{Q}_{\mathrm{s}} \mathrm{k}_{\mathrm{p} / 2}}{\mathrm{~m}} \Psi_{\mathrm{r}} \\
\mathrm{L}_{\lambda, \mathrm{r}}^{\prime}=\frac{\mathrm{n}_{\mathrm{s}}{ }^{2} \mathrm{Q}_{\mathrm{s}}{ }^{2} \mathrm{k}_{\mathrm{p} / 2}{ }^{2}}{\mathrm{Q}_{\mathrm{r}} \mathrm{m}} \mathrm{L}_{\lambda, \mathrm{r}}
\end{gathered}
$$

\section{Steady-state Equivalent-circuit WICSC Machine Model}

With the help of (16) and (17), the stator-phase voltage phasor, $\bar{V}_{\mathrm{S}}$, and the rotor-bar voltage phasor in the stator reference frame, $\overline{\mathrm{V}}_{\mathrm{r}}$, of the WICSC machine can be expressed using the following equations:

$$
\begin{gathered}
\bar{V}_{s}=R_{s} \bar{I}_{s, 1}+j \omega_{s} L_{\lambda, s} \bar{I}_{s, 1}+j \omega_{s} L_{m}\left(\bar{I}_{s, 1}+\bar{I}_{r, 1}^{\prime}\right) \\
\bar{V}_{r}=\frac{n_{s} Q_{s} k_{p / 2} R_{r, 1}}{Q_{r} s} \bar{I}_{r, 1}^{\prime}+\frac{j \omega_{s l i p}}{s} \bar{\psi}_{r, 1}^{\prime} \frac{m}{n_{s} Q_{s} k_{p / 2}}
\end{gathered}
$$

where $\overline{\mathrm{I}}_{\mathrm{s}, 1}$ and $\overline{\mathrm{I}}_{\mathrm{r}, 1}^{\prime}$ are the stator-phase and rotor-bar current phasors respectively, $\mathrm{R}_{\mathrm{S}}$ the per-phase stator resistance and $R_{r}$ the resistance of a single rotor bar (taking into account the corresponding short-circuit ring segments). It should be mentioned that the length of the end winding in the WICSC machine can be easily determined due to the simplicity of the used Gramme-type winding. Thus, contrary to the case of the conventional induction machine, $\mathrm{R}_{\mathrm{s}}$ can be estimated with great accuracy by taking into account the axial-end effects.
Since the rotor bars are short circuited by the two shortcircuit rings on each axial end of the rotor, $\overline{\mathrm{V}}_{\mathrm{r}}=0$. If the following quantity is also defined:

$$
\mathrm{R}_{\mathrm{r}}^{\prime}=\frac{\mathrm{n}_{\mathrm{s}}^{2} \mathrm{Q}_{\mathrm{s}}{ }^{2} \mathrm{k}_{\mathrm{p} / 2}{ }^{2}}{\mathrm{Q}_{\mathrm{r}}} \mathrm{R}_{\mathrm{r}}
$$

the corresponding voltage equation for the rotor (23) can eventually be restated as:

$$
0=\frac{\mathrm{R}_{\mathrm{r}}}{\mathrm{s}} \overline{\mathrm{I}}_{\mathrm{r}, 1}^{\prime}+\mathrm{j} \omega_{\mathrm{s}} \mathrm{L}_{\lambda, \mathrm{r}}^{\prime}{\overline{\mathrm{I}^{\prime}}}_{\mathrm{r}, 1}+\mathrm{j} \omega_{\mathrm{s}} \mathrm{L}_{\mathrm{m}}\left(\overline{\mathrm{I}}_{\mathrm{s}, 1}+{\overline{\mathrm{I}^{\prime}, 1}}_{\mathrm{r}}\right)
$$

The final equation in order to adequately describe the equivalent-circuit of the WICSC machine model, shown in Fig. 3 , is the stator-impedance per phase $\overline{\mathrm{Z}}_{\mathrm{s}}$ :

$$
\bar{Z}_{s}=\frac{\bar{v}_{s}}{\bar{I}_{s, 1}}=R_{s}+j \omega_{s} L_{\lambda, s}+\frac{j \omega_{s} L_{m}\left(\frac{R \prime r}{s}+j \omega_{s} L^{\prime} \lambda, r\right)}{\frac{R / r}{s}+j \omega_{s}\left(L^{\prime} \lambda, r+L_{m}\right)}
$$

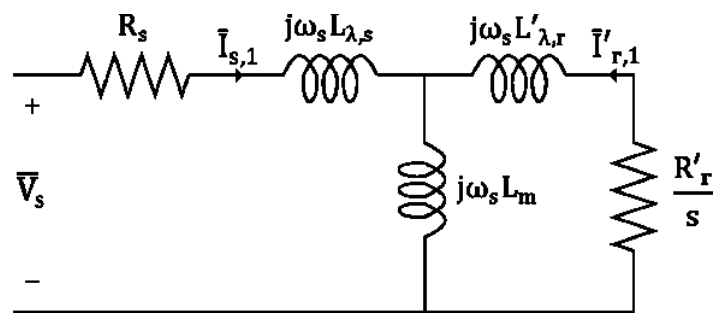

Fig. 3. The steady-state equivalent-circuit of the WICSC machine model.

\section{E. Derivation of Electromagnetic Torque}

The resistance on the rotor side of the equivalent circuit can be divided in two terms as follows:

$$
\frac{\mathrm{R}^{\prime} \mathrm{r}}{\mathrm{s}}=\mathrm{R}_{\mathrm{r}}^{\prime}+\left(\frac{1-\mathrm{s}}{\mathrm{s}}\right) \mathrm{R}_{\mathrm{r}}^{\prime}
$$

The second term of the above equation represents the mechanical power, $\mathrm{P}_{\text {mech }}$, developed by the rotor on the shaft of the WICSC machine. With amplitude-invariant phasor scaling, $\mathrm{P}_{\text {mech }}$ can therefore be expressed as [9]:

$$
\mathrm{P}_{\mathrm{mech}}=\frac{\mathrm{m}}{2}\left(\frac{1-\mathrm{s}}{\mathrm{s}}\right) \mathrm{R}_{\mathrm{r}}^{\prime}\left|\overline{\mathrm{I}}_{\mathrm{r}, 1}^{\prime}\right|^{2}
$$

Hence, the developed electromagnetic torque can be derived based on the previous analysis:

$$
\mathrm{T}_{\mathrm{e}}=\frac{\mathrm{mp}}{4} \mathrm{~L}_{\mathrm{m}, 1} \hat{1}_{\mathrm{s}}^{2} \frac{\frac{\mathrm{L}_{\mathrm{m}} \omega_{\text {slip }}}{\mathrm{R} / \mathrm{r}}}{1+\left(\frac{\mathrm{L}_{\mathrm{m}} \omega_{\text {slip }}}{\mathrm{R} / \mathrm{r}}\right)^{2}}
$$

\section{F. Analytical Investigation of Pole-Changing and Phase- Changing Capability}

In automotive applications, a wide speed-range operation is an important requirement. As already underlined in Section I, the topology of the WICSC machine exhibits the inherent ability of changing the number of poles and active phases during operation. Therefore, by properly adjusting the number of poles or/and phases at different operating speeds, optimum efficiency can be achieved over the entire torque-speed envelope [10].

This useful property will be exemplified for simplicity in the case of attaining the maximum electromagnetic torque, 
$\mathrm{T}_{\mathrm{e} \text {,max }}$. According to (29), $\mathrm{T}_{\mathrm{e} \text {,max }}$ occurs when $\mathrm{L}_{\mathrm{m}} \omega_{\text {slip }}=\mathrm{R}_{\mathrm{r}}^{\prime}$ and is, thus, given by the following equation:

$$
\mathrm{T}_{\mathrm{e}, \max }=\frac{\mu_{0} \mathrm{n}_{\mathrm{s}}{ }^{2} \mathrm{Q}_{\mathrm{s}}{ }^{2} \mathrm{~L}_{\mathrm{a}} \mathrm{r}_{\mathrm{r}} \mathrm{k}_{\mathrm{p} / 2}{ }^{2}}{2 \pi \delta \mathrm{p}} \hat{\mathrm{l}}_{\mathrm{s}}^{2}
$$

In the case of achieving the same $\mathrm{T}_{\mathrm{e}, \max }$ with different pole numbers, $p$ and $p^{\prime}$ in a specific WICSC machine topology, the required stator current amplitude should be scaled as follows:

$$
\hat{\mathrm{l}}_{\mathrm{s}}{ }^{\prime}=\frac{\mathrm{n}_{\mathrm{s}} \mathrm{k}_{\mathrm{p} / 2}}{\mathrm{n}_{\mathrm{s}}{ }^{\prime} \mathrm{k}_{\mathrm{p} / 2}{ }^{\prime}} \sqrt{\frac{\mathrm{p}^{\prime}}{\mathrm{p}}} \hat{\mathrm{l}}_{\mathrm{s}}
$$

It is easily understood that for a specific WICSC machine topology, the number of turns $\mathrm{n}_{\mathrm{s}}$ cannot be changed during operation.

For acquiring the same maximum torque capability from winding layouts with different number of phases, $\mathrm{m}$ and $\mathrm{m}$ ', the required stator current amplitude can be computed according to the formula:

$$
\hat{\mathrm{i}}_{\mathrm{s}}^{\prime}=\frac{\mathrm{n}_{\mathrm{s}} \mathrm{k}_{\mathrm{p} / 2}}{\mathrm{n}_{\mathrm{s}} \mathrm{k}_{\mathrm{p} / 2}{ }^{\prime}} \hat{\mathrm{l}}_{\mathrm{s}}
$$

\section{NUMERICAL INVESTIGATION}

\section{A. Winding Layout}

The electrical periodicity of the machine, $t_{p e r}$, is defined as the greatest common divisor of the number of stator slots, $\mathrm{Q}_{\mathrm{s}}$ and the number of poles, $\mathrm{p}$ :

$$
t_{\text {per }}=G C D\left(Q_{s}, p / 2\right)
$$

It can be deduced that $t_{\text {per }}$ denotes also the number of winding symmetries.

In this analysis, the winding layout of the WICSC machine is decided with the aim to maximize the MMF main harmonic $(\mathrm{h}=\mathrm{p} / 2)$. The applied method is based on the principle of the star of slots, which corresponds to the phasor representation of the main electromagnetic (EMF) harmonic induced in the coils of each stator slot [11]. The diagram of the star of slots includes $Q_{s} / t_{\text {per }}$ spokes, with each spoke consisting of $t_{\text {per }}$ phasors, and thus, reduces the machine model to its equivalent 2-pole model by taking advantage of the per-pole-pair symmetry. A modification is introduced in the star-of-slots design rules in order to adapt to the polesymmetric fundamental winding configuration: the angular displacement between the phases is considered $\pi / \mathrm{m}$ rather than $2 \pi / \mathrm{m}$. This technique is exemplified in Fig. 4 for a 12-slot, 20-pole and 3-phase (double-layer, fractional-slot concentrated) WICSC machine. The resulting star of slots is presented in Fig. 4a, where the numbers of the stator slots corresponding to each spoke are indicated with dark red color. Furthermore, the stator winding layout along the stator periphery and the produced MMF due to the stator winding configuration are shown in Fig. 4b and Fig. 4c respectively.

\section{B. Numerical Verification of Pole-Changing and Phase- Changing Capability}

In Section II-F, the required stator-current was estimated in order to attain the desired torque output while adjusting the

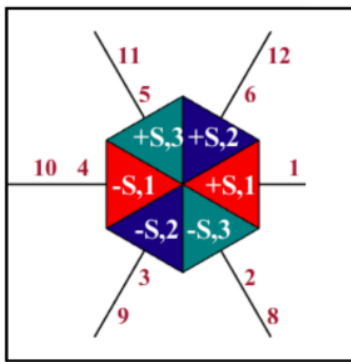

(a)

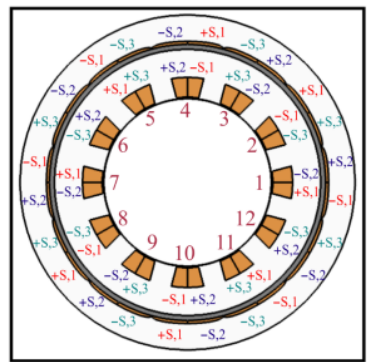

(b)

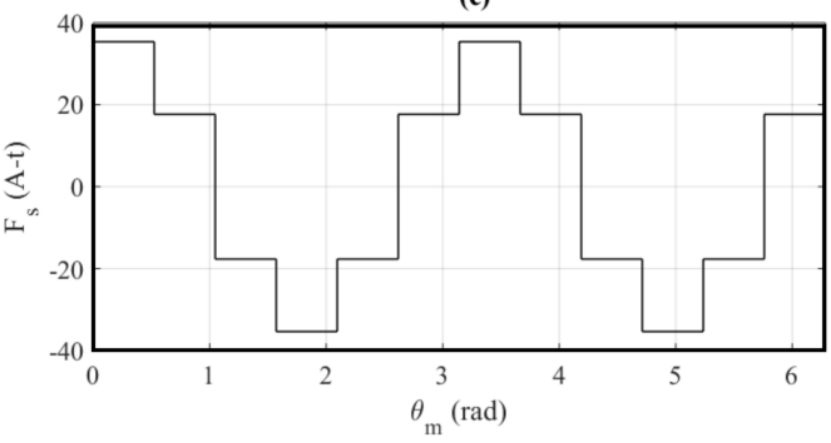

Fig. 4. (a) Star of slots, (b) winding layout and (c) stator MMF distribution of a 12-slot, 20-pole and 3-phase WICSC machine.

number of poles and active phases. That analysis needs to be validated numerically. For this purpose, the WICSC geometry of 36 stator slots and 26 rotor bars, which is depicted in Fig. 1a, was selected and analyzed. The electromagnetic analysis of the FE models is performed using the FE software COMSOL Multiphysics ${ }^{1}$, while MATLAB ${ }^{2}$ is used as a scripting tool for processing the COMSOL models.

At first, the model is simulated for a 3-phase stator winding layout with different number of poles: $p=2, p=4$ and $p=6$, while $\hat{i}_{s}$ is properly adjusted according to (31) (the number of turns $n_{s}$ is constant). The result of this analysis is shown in Fig. 5, where it is visible that there is a small deviation in the value of the maximum torque computed from the models with different pole number. This deviation can be deemed acceptable, considering the simplifying assumptions of the analytical approach.

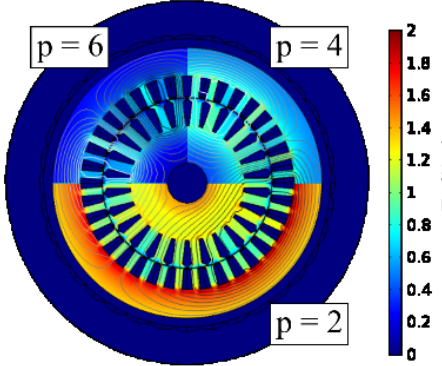

(a)

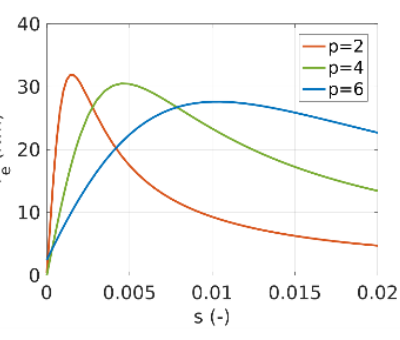

(b)
Fig. 5. (a) Produced magnetic field density at the maximum torque and (b) output torque versus slip graph for different number of poles in a 36-slot, 3-phase WICSC machine.

In addition, the investigation with different number of phases is performed for 4-pole stator winding layout and $\mathrm{m}=$ 3 and $\mathrm{m}=6$. This time, $\hat{\mathrm{s}}_{\mathrm{s}}$ is scaled according to (32) depending on the calculated winding factors, $\mathrm{k}_{\mathrm{p} / 2}$ of the different winding layouts. As it can be observed in Fig. 6, the

${ }^{1}$ Comsol Multiphysics ${ }^{\circledR}$ is a registered trademark of Comsol AB, Stockholm, Sweden.

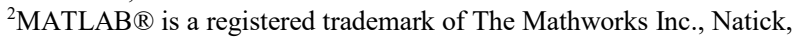
Ma, USA. 
two WICSC model produce identical maximum torque. The proper adjusting of phases while maintaining constant torque is, thus, achievable and (32) holds.

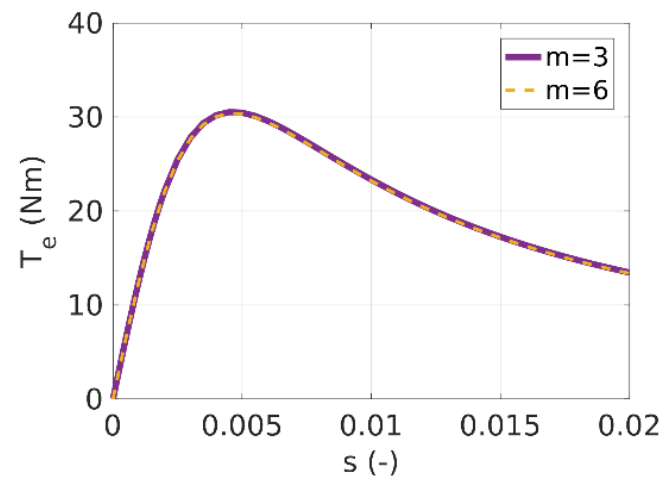

Fig. 6. Output torque versus slip graph for different number of phases, $\mathrm{m}=$ 3 and $\mathrm{m}=6$, in a 36-slot, 4-pole WICSC machine.

\section{CONVERTER Output Voltage CONSIDERAtions}

In order to properly design and size a WICSC machine, it is crucial to consider also the design of the converter topology. Since each stator coil (i.e., coil corresponding to each stator slot) is controlled independently, it should be connected to an individual converter leg, as it is illustrated in Fig. 7.

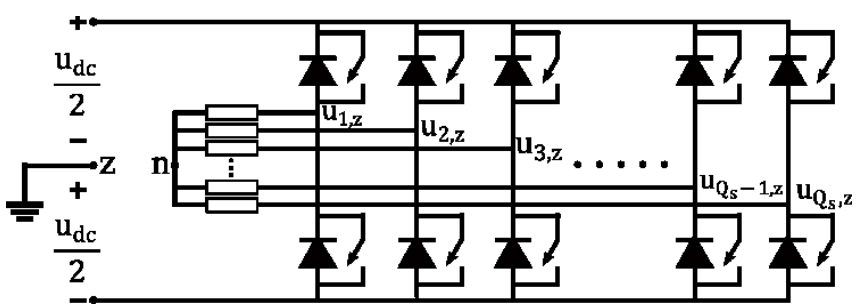

Fig. 7. Schematic of an m-phase bridge-type voltage source inverter.

If each slot index is denoted with $\kappa=1,2, \ldots, Q_{s}$, the converter output voltage $u_{\kappa, z}$ for slot $\kappa$ is then:

$$
\mathrm{u}_{\kappa, \mathrm{z}}=\mathrm{s}_{\kappa} \frac{\mathrm{u}_{\mathrm{dc}}}{2}
$$

where $s_{k}= \pm 1$, assuming that the dc-link voltage of the converter is grounded in its midpoint $\mathrm{z}$. Moreover, if $\mathrm{u}_{\kappa, \mathrm{n}}$ is the coil voltage in slot $\kappa$, the following expression holds:

$$
-\sum_{\kappa=1}^{\mathrm{Q}_{\mathrm{s}}} \mathrm{u}_{\kappa, \mathrm{z}}+\sum_{\kappa=1}^{\mathrm{Q}_{\mathrm{s}}} \mathrm{u}_{\kappa, \mathrm{n}}+\mathrm{Q}_{\mathrm{s}} \mathrm{u}_{\mathrm{n}, \mathrm{z}}=0
$$

The assumption of a balanced current excitation entails that for each stator coil, there is a corresponding coil with equal voltage magnitude and opposite sign. Thus, the following can be derived:

$$
\begin{gathered}
\sum_{\mathrm{K}=1}^{\mathrm{Q}_{\mathrm{s}}} \mathrm{u}_{\mathrm{K}, \mathrm{n}}=0 \\
\sum_{\mathrm{K}=1}^{\mathrm{Q}_{\mathrm{s}}} \mathrm{s}_{\mathrm{K}}=0
\end{gathered}
$$

From the above, (35) can be re-rexpressed as:

$$
\mathrm{u}_{\mathrm{n}, \mathrm{z}}=\frac{\sum_{\kappa=1}^{\mathrm{Q}_{\mathrm{s}}} \mathrm{u}_{\kappa, \mathrm{z}}}{\mathrm{Q}_{\mathrm{s}}}
$$

As a result, the coil voltage in slot $\kappa$ is:

$$
\mathrm{u}_{\mathrm{\kappa}, \mathrm{n}}=\mathrm{u}_{\mathrm{\kappa}, \mathrm{z}}-\mathrm{u}_{\mathrm{n}, \mathrm{z}}=\frac{\mathrm{u}_{\mathrm{dc}}}{2}\left(\mathrm{~s}_{\mathrm{\kappa}}-\frac{\sum_{\mathrm{K}=1}^{\mathrm{Q}_{\mathrm{s}}} \mathrm{s}_{\mathrm{K}}}{\mathrm{Q}_{\mathrm{s}}}\right)=\mathrm{s}_{\mathrm{\kappa}} \frac{\mathrm{u}_{\mathrm{dc}}}{2}
$$

Hence, the coil voltage limit of a WICSC machine is:

$$
\left|\mathrm{u}_{\kappa, \mathrm{n}}\right| \leq \frac{\mathrm{u}_{\mathrm{dc}}}{2}
$$

\section{CONCLUSION}

This paper presents the geometry of an induction machine with wound independently-controlled stator coils. The steadystate equivalent-circuit of the WICSC machine model is derived, by expressing the stator excitation based on the polesymmetric fundamental winding configuration. In addition, the useful capability of changing the number of poles and active phases in the WICSC machine during operation is investigated. The numerical analysis of WICSC FE models for utilizing the pole-changing and phase-changing ability provide results that harmonize considerably with the analytical approach.

\section{REFERENCES}

[1] V. Monteiro et al., "Vehicle Electrification: New Challenges and Opportunities for Smart Grids," in Energies, vol. 12, Dec 2018.

[2] G. Dajaku and D. Gerling, "Low costs and high efficiency asynchronous machine with stator cage winding," 2014 IEEE International Electric Vehicle Conference (IEVC), Florence, 2014.

[3] F. Bachheibl and D. Gerling, "High-current, low-voltage power net," 2014 IEEE International Electric Vehicle Conference (IEVC), Florence, 2014.

[4] A. Baumgardt et al., "48V traction: Innovative drive topology and battery," 2016 IEEE International Conference on Power Electronics, Drives and Energy Systems (PEDES), Trivandrum, 2016, pp. 1-6.

[5] G. Henneberger and M. Bork, "Development of a new transverse flux motor," IEE Colloquium on New Topologies for Permanent Magnet Machines, London, UK, 1997.

[6] T A. A. Rockhill and T. A. Lipo, "A generalized transformation methodology for polyphase electric machines and networks," 2015 IEEE International Electric Machines \& Drives Conference (IEMDC), Coeur d'Alene, ID, 2015.

[7] A. Tessarolo, "Modeling and analysis of multi-phase electric machines for high-power applications, " Ph.D. dissertation, Dept. of Industrial Engineering, University of Padova, Italy, 2011.

[8] T. A. Lipo, "Introduction to AC machine design," Madison, Wisconsin: Wisconsin Power Electronics Research Center, University of Wisconsin, 2004.

[9] S. Uman, "Fitzgerald and Kingsley's Electric Machinery, " Boston, Mass: McGraw-Hill, 2014.

[10] A. Patzak et. al, "Driving range evaluation of a multi-phase drive for low voltage high power electric vehicles," 2015 International Conference on Sustainable Mobility Applications, Renewables and Technology (SMART), Kuwait City, 2015,

[11] N. Bianchi and M. Dai Pre, "Use of the star of slots in designing fractional-slot single-layer synchronous motors," in IEE Proceedings - Electric Power Applications, vol. 153, no. 3, pp. 459-466, May 2006. 